SUPPORTING INFORMATION FOR:

\title{
Study of Perovskite QD Down-Converted LEDs and Six-Color White LEDs for Future Displays with Excellent Color Performance
}

Hee Chang Yoon ${ }^{\dagger}$, Heejoon Kang ${ }^{\dagger}$, Soyoung Lee ${ }^{\dagger}$, Ji Hye Oh ${ }^{\dagger}$, Heesun Yang ${ }^{\ddagger}$ and Young Rag $D o^{\dagger, *}$

${ }^{\dagger}$ Department of Chemistry, Kookmin University, Seoul 136-702, Republic of Korea

${ }^{\ddagger}$ Department of Materials Science and Engineering, Hongik University, Seoul 121-791, Republic of Korea

E-mail: yrdo@kookmin.ac.kr 

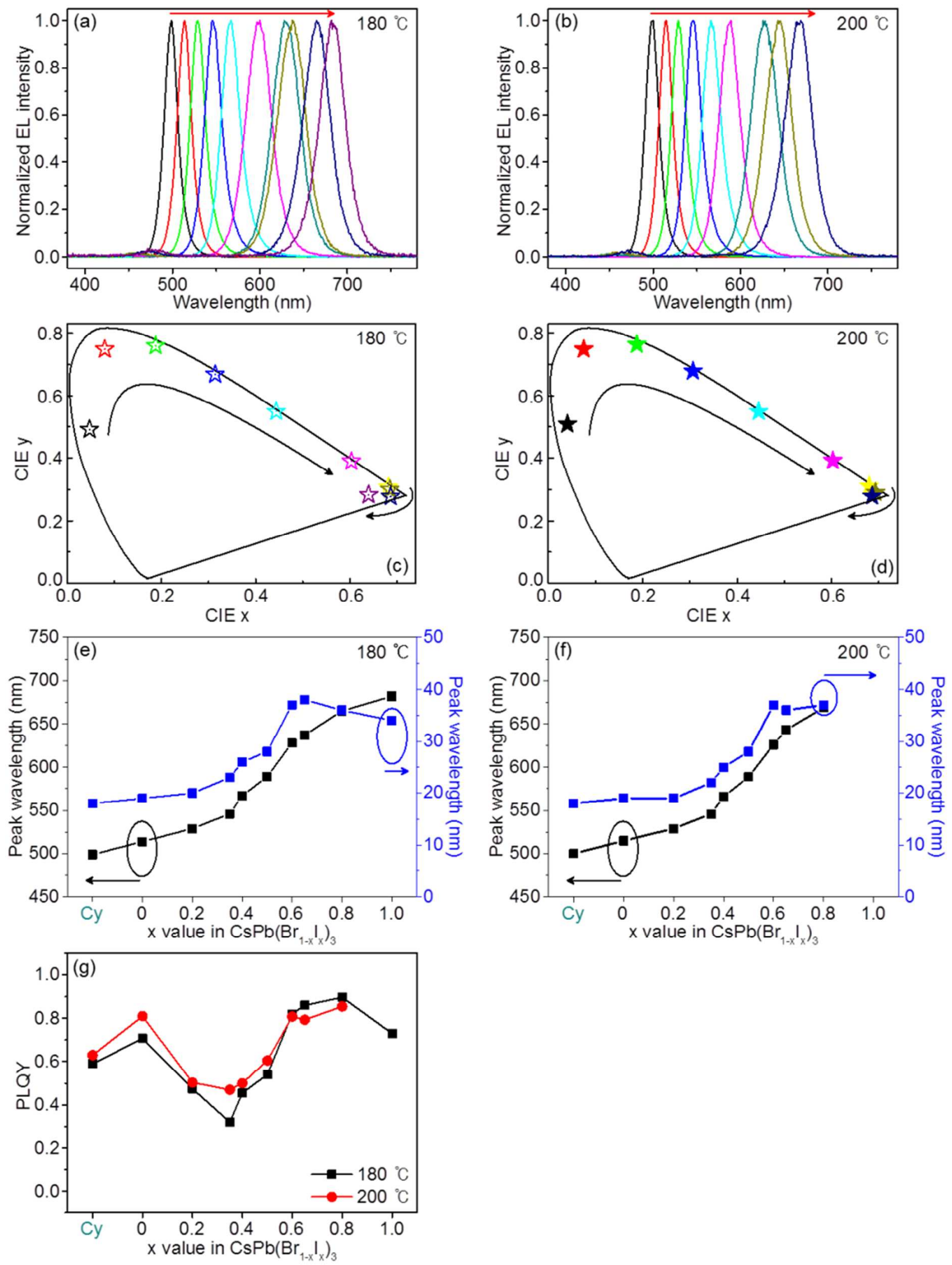

Figure S1. (a), (b) PL-emitting spectrum, (c), (d) CIE color coordinates, and (e), (f) peak wavelength and full-width at half-maximum (FWHM) of $\mathrm{CsPb}\left(\mathrm{Br}_{1-\mathrm{x}} \mathrm{I}_{\mathrm{x}}\right)_{3}(\mathrm{x}=0,0.2,0.35,0.4$, $0.5,0.6,0.65,0.8,1.0)$ and $\mathrm{CsPb}\left(\mathrm{Br}_{0.75} \mathrm{Cl}_{0.25}\right)_{3}(\mathrm{Cy}) \mathrm{PeQDs}$ synthesized at $180^{\circ} \mathrm{C}$ and $200^{\circ} \mathrm{C}$, 
respectively. (g) PLQY of all synthesized $\mathrm{CsPbX}_{3}$ PeQDs. Red arrows indicate the direction from the $\mathrm{CsPb}\left(\mathrm{Br}_{0.75} \mathrm{Cl}_{0.25}\right)_{3} \mathrm{PeQD}$ spectrum to the $\mathrm{CsPb}\left(\mathrm{Br}_{1-\mathrm{x}} \mathrm{I}_{\mathrm{x}}\right)_{3}$ spectra with an increase in the $\mathrm{x}$ value. 
(a)

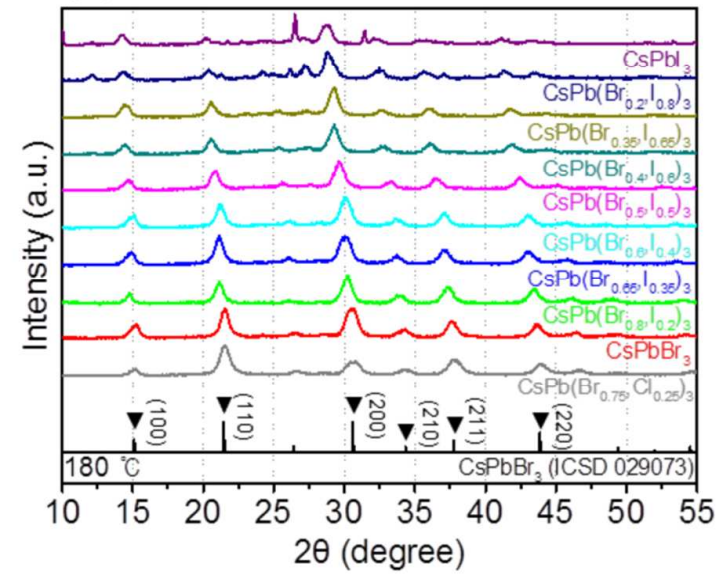

(b)

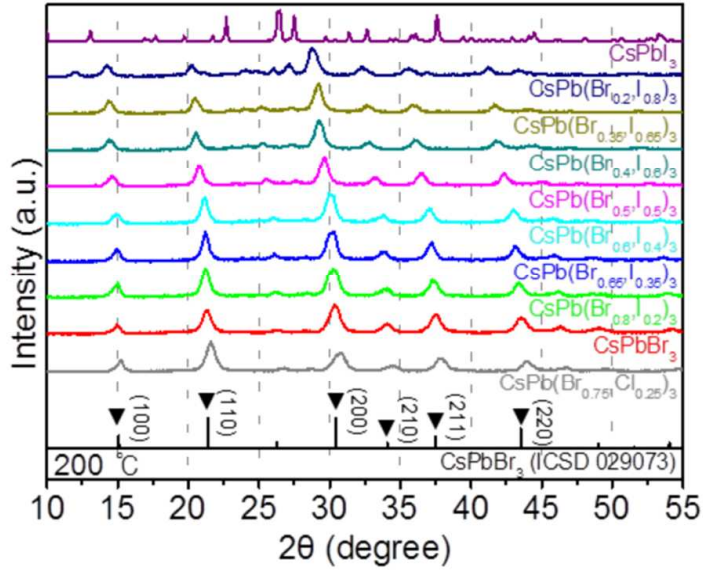

(c)
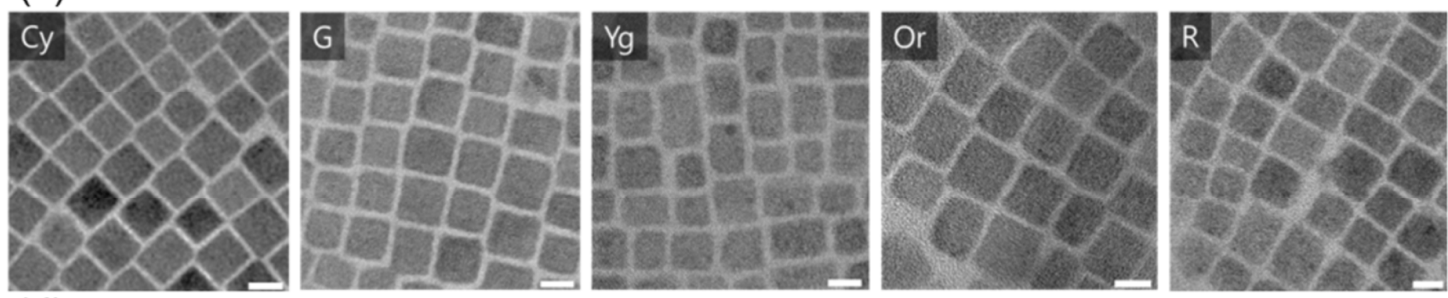

(d)
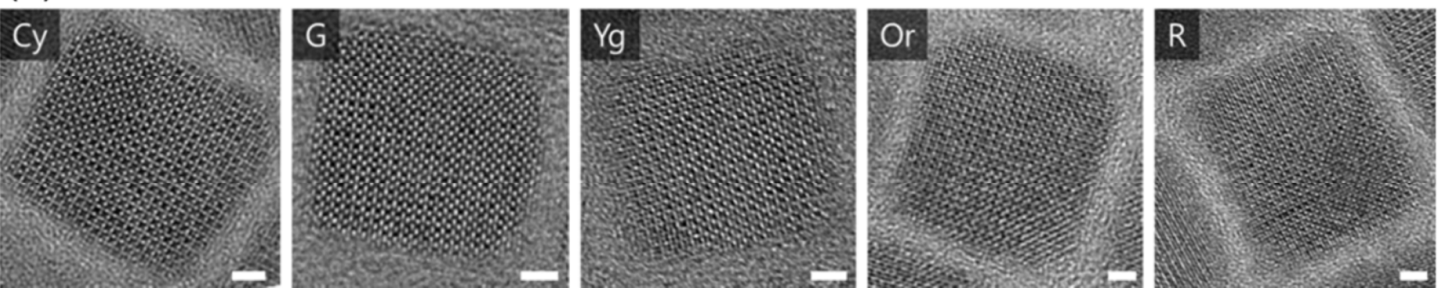

Figure S2. (a) and (b) X-ray diffraction patterns of $\mathrm{CsPb}\left(\mathrm{Br}_{1-\mathrm{x}} \mathrm{I}_{\mathrm{x}}\right)_{3}(\mathrm{x}=0,0.2,0.35,0.4,0.5$, $0.6,0.65,0.8,1.0)$ and $\operatorname{CsPb}\left(\mathrm{Br}_{0.75} \mathrm{Cl}_{0.25}\right)_{3}$ QDs synthesized at $180{ }^{\circ} \mathrm{C}$ and $200{ }^{\circ} \mathrm{C}$, respectively. The black XRD pattern is the $\mathrm{CsPbBr}_{3}$ ICSD peak (029073). (c) Lowmagnification (10 $\mathrm{nm}$ white scale bar) and (d) high-magnification ( $2 \mathrm{~nm}$ white scale bar) HRTEM images of $\operatorname{CsPb}\left(\mathrm{Br}_{0.75}, \mathrm{Cl}_{0.25}\right)_{3} \quad$ (Cy), $\mathrm{CsPbBr}_{3} \quad(\mathrm{G}), \quad \mathrm{CsPb}\left(\mathrm{Br}_{0.65}, \mathrm{I}_{0.35}\right)_{3} \quad(\mathrm{Yg})$, $\mathrm{CsPb}\left(\mathrm{Br}_{0.5}, \mathrm{I}_{0.5}\right)_{3}(\mathrm{Or})$, and $\mathrm{CsPb}\left(\mathrm{Br}_{0.35}, \mathrm{I}_{0.65}\right)_{3}(\mathrm{R}) \mathrm{PeQDs}$ prepared at $200{ }^{\circ} \mathrm{C}$. 


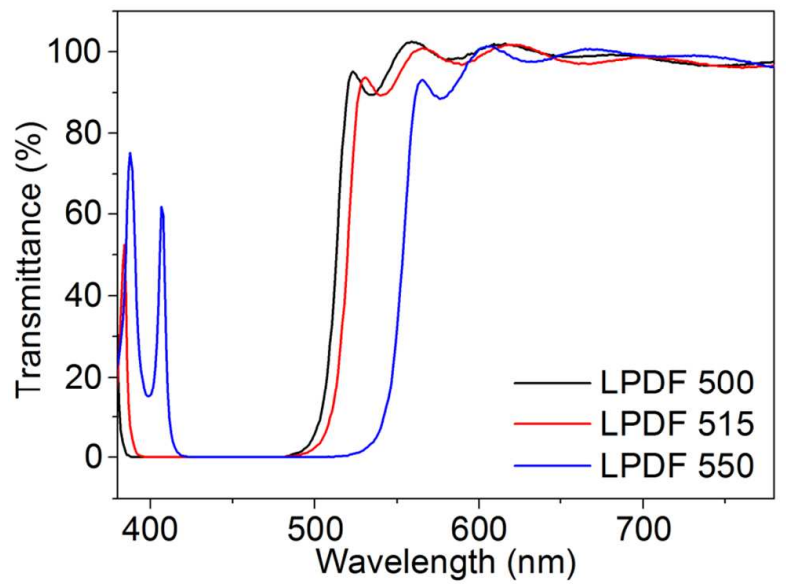

Figure S3. Transmittances of three types of LPDFs covering a CGYOR-emitting monochromatic LED. The numerical value of the LPDFs indicates the half-band-edge wavelength. 

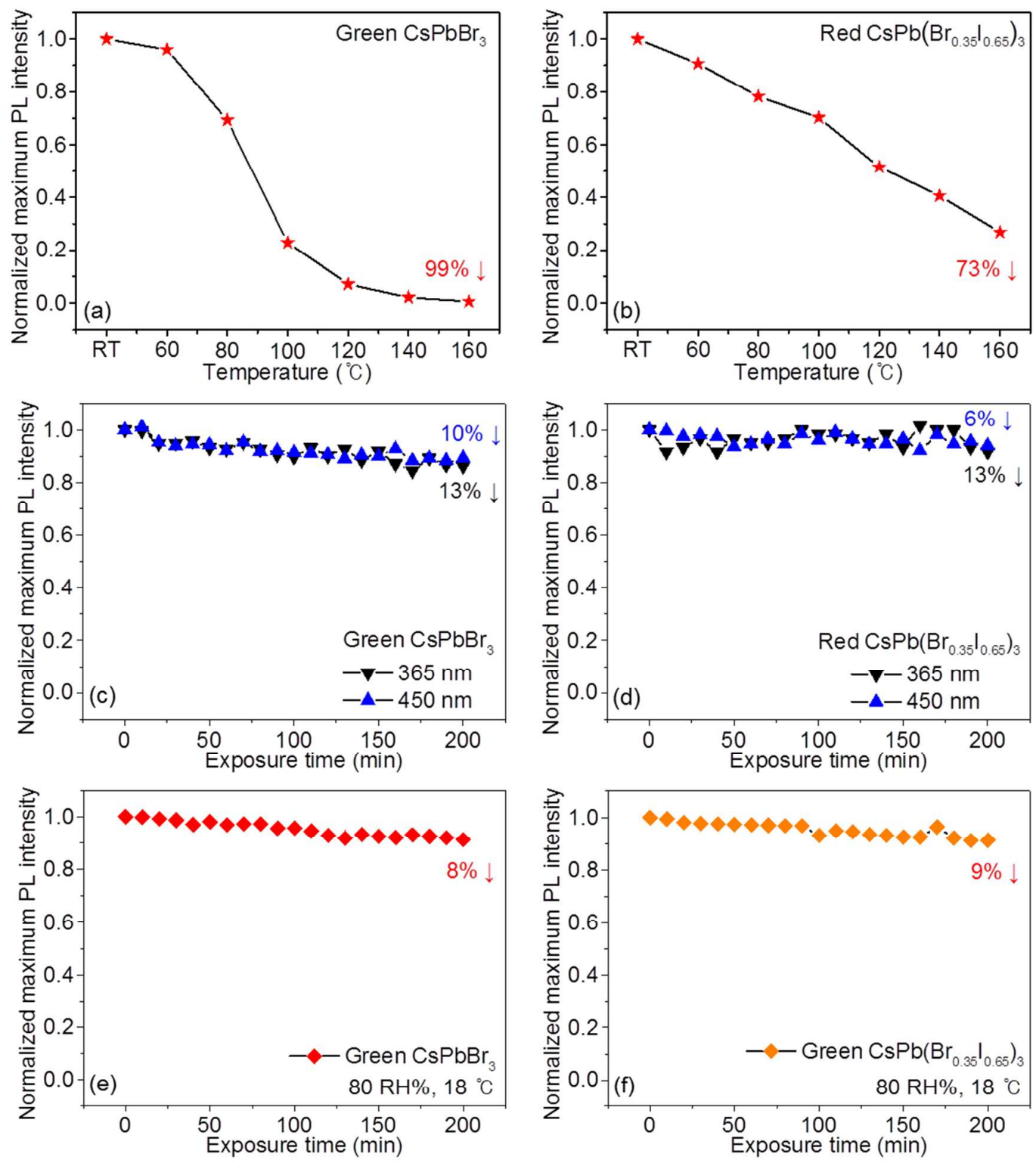

Figure S4. Normalized maximum PL intensity of thermal-processed (a) $\mathrm{CsPbBr}_{3}$ and (b) $\mathrm{CsPb}\left(\mathrm{Br}_{0.35} \mathrm{I}_{0.65}\right)_{3}$ PeQDs/polymer (thermal curing polymer, OE-6636, Dow Corning Co.) pastes (temperature from 60 to $160{ }^{\circ} \mathrm{C}$ with a $20{ }^{\circ} \mathrm{C}$ interval). Normalized maximum PL intensities of (c) $\mathrm{CsPbBr}_{3}$ and (d) $\mathrm{CsPb}\left(\mathrm{Br}_{0.35} \mathrm{I}_{0.65}\right)_{3}$ PeQDs/NOA 63 films exposed to excitation wavelengths of $365 \mathrm{~nm}$ and $450 \mathrm{~nm}$ (exposure times up to $200 \mathrm{~min}$ ). Normalized maximum PL intensities of (e) $\mathrm{CsPbBr}_{3}$ and (f) $\mathrm{CsPb}\left(\mathrm{Br}_{0.35} \mathrm{I}_{0.65}\right)_{3}$ PeQDs/NOA 63 films in an $80 \mathrm{RH} \%, 18{ }^{\circ} \mathrm{C}$ atmosphere. 


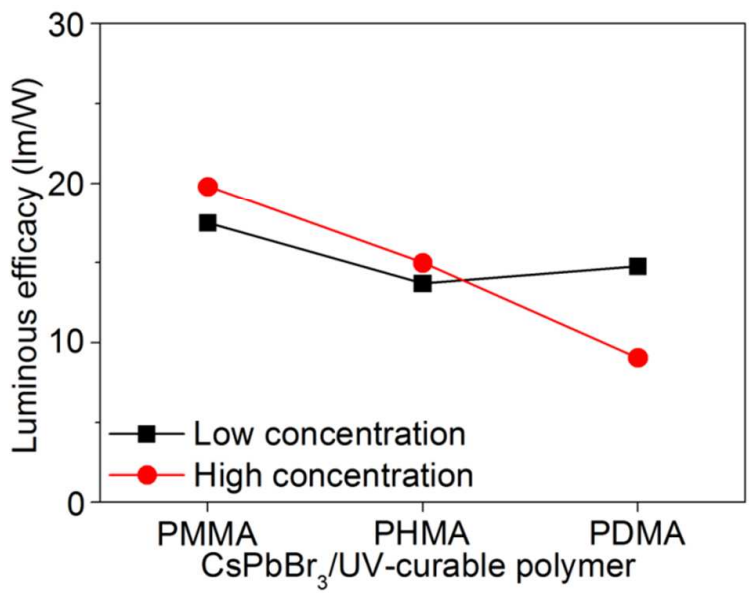

Figure S5. Luminous efficacies $(\mathrm{lm} / \mathrm{W})$ of $\mathrm{CsPbBr}_{3} \mathrm{G}$ peQD and three types (MMA, HMA, and DMA) of methacrylate hybrid monochromatic DC-LEDs at $20 \mathrm{~mA}$.

To compare the NOA 63 with other UV-curable binders with regard to its suitability for use with PeQD, we fabricated PeQD-based down-converted LEDs (DC-LEDs) using three types of UV-curable polymers (photoinitiator-mixed methyl methacrylate, hexyl methacrylate, and dodecyl methacrylate). However, we noted several problems when attempting to use these methacrylate-based polymers as a UV-curable binder. First, the overall curing time of the $\mathrm{PeQD} /$ methacrylate-based UV-curable polymer mixture is at least 60 minutes (120 minutes for perfect bonding). This curing time is too long to form a solid PeQD-embedded binder. Second, the solution phase of each methacrylate-based UV-curable polymer evaporated slightly during the UV-curing process. That is why it is difficult to control the condensation and concave-surface problem. Finally, aggregation was noted after a curing process with a high concentration of the PeQD solution. A high concentration of PeQD solution is necessary to fabricate monochromatic DC-LEDs. Therefore, as shown in Figure S5, we measured the optical efficiencies of the PeQD/methacrylate-based down-converted LEDs using low- and high-concentration PeQDs, resulting in no aggregation. 

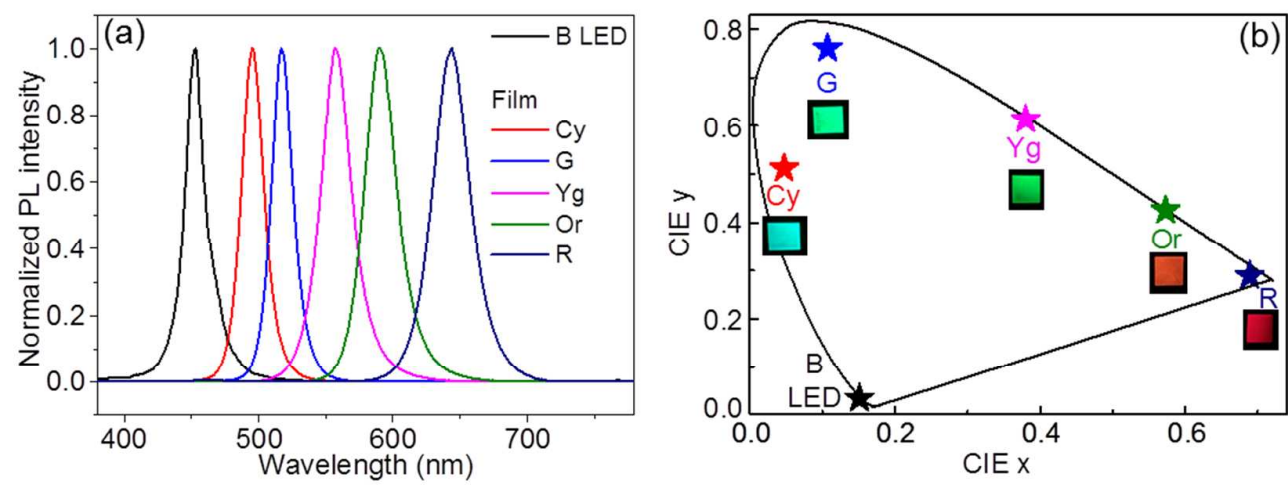

Figure S6. (a) Normalized PL spectra and (b) color coordinates of $\mathrm{CsPb}\left(\mathrm{Br}_{0.75}, \mathrm{Cl}_{0.25}\right)_{3}$ (Cy),

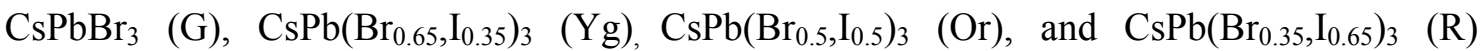
PeQD/NOA 63 composite films.
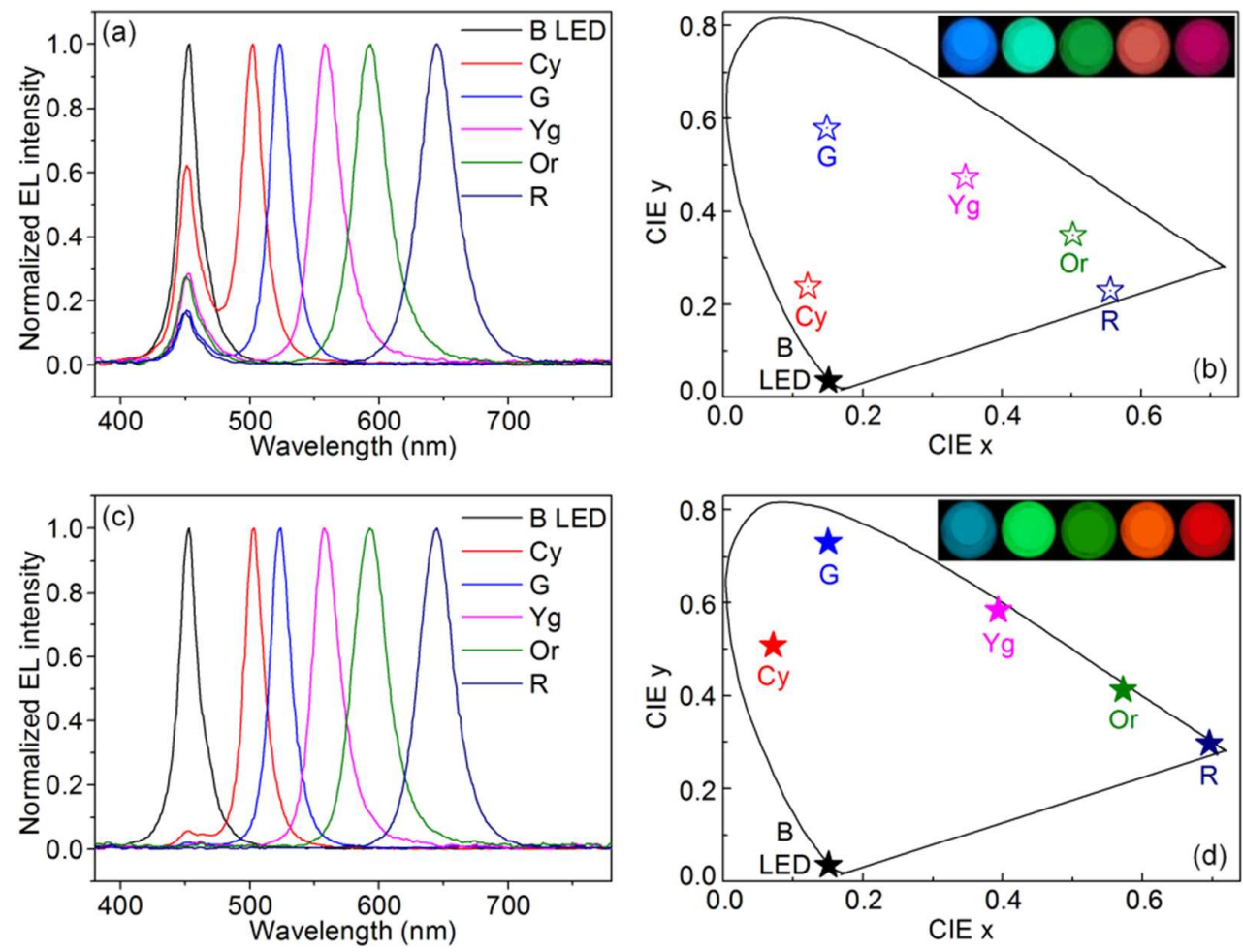

Figure S7. (a) EL spectrum, (b) CIE color coordinates of $\mathrm{CsPb}\left(\mathrm{Br}_{0.75}, \mathrm{Cl}_{0.25}\right)_{3} \mathrm{Cy}$-, $\mathrm{CsPbBr} 3$ G-, $\mathrm{CsPb}\left(\mathrm{Br}_{0.65}, \mathrm{I}_{0.35}\right)_{3}$ Yg-, $\mathrm{CsPb}\left(\mathrm{Br}_{0.5}, \mathrm{I}_{0.5}\right)_{3}$ Or-, and $\mathrm{CsPb}\left(\mathrm{Br}_{0.35}, \mathrm{I}_{0.65}\right)_{3}$ R-emitting PeQDsbased emitting DC-LEDs without LPDFs, (c) EL spectrum, (d) CIE color coordinates of CGYOR-emitting DC-LEDs with LPDFs, inset of (b), (d): photographs of the EL emissions of CGYOR DC-LEDs with and without LPDFs. 